\title{
Paddy plants inoculated with PGPR show better growth physiology and nutrient content under saline conditions
}

\author{
Yachana Jha $^{1^{*} \text {, and R.B.Subramanian }}{ }^{2}$
}

\begin{abstract}
The possible role of plant growth-promoting rhizobacteria (PGPR) to alleviate salt stress during plant growth has been studied on paddy rice (Oryza sativa L.) 'GJ-17' under greenhouse conditions; the study included growth parameters, mineral concentration, and antioxidant enzyme level. Salinity reduced plant growth, but PGPR inoculation reduced its harmful effect up to $1 \%$ salinity. Plants inoculated with PGPR under saline conditions showed $16 \%$ higher germination, $8 \%$ higher survival, 27\% higher dry weight, and 31\% higher plant height. Similarly, PGPR inoculated plants showed increased concentrations of $\mathrm{N}(26 \%), \mathrm{P}(16 \%), \mathrm{K}(31 \%)$, and reduced concentrations of $\mathrm{Na}(71 \%)$ and Ca (36\%) as compared to non-inoculated control plants under saline conditions. Plants inoculated with PGPR under saline conditions also showed significant variations in antioxidant levels and growth physiology. Results suggested that inoculation with PGPR Bacillus pumilus and Pseudomonas pseudoalcaligenes in salt-stressed plants could help to alleviate salt stress in the paddy.
\end{abstract}

Key words: Antioxidant, catalase, mineral concentration, Oryza sativa, RAPD analysis, superoxide dismutase.

\section{INTRODUCTION}

Since plants are sessile, their growth and yield are strongly influenced by abiotic stress such as drought, high salt content, and temperature change. Environmental stress is a major challenge in the world quest for sustainable food production since it reduces potential yields by as much as $70 \%$ in crop plants. Plants under salt stress can suffer from membrane destabilization and general nutrient imbalance. Salinity produces oxidative stress by the enhanced occurrence of reactive oxygen species (ROS) (Zhu et al., 2007), which act both as the damaging toxic molecule and the beneficial signal transduction molecule (Miller et al., 2010). In order to adjust the cellular redox state and reduce the toxic effect of salinity, the plant's antioxidant system has to be activated. Antioxidant enzymes that control biosynthesis and utilization of antioxidant metabolites to detoxify ROS (Foyer and Noctor, 2005) intricately regulate antioxidant capacity. Reactive oxygen species are thought to be key inducers of programmed cell death in plants (De Pinto et al., 2012) and antioxidants play an important role in this process ( $\mathrm{Li}$ et al., 2007). To protect against oxidative stress, plant cells produce antioxidant enzymes such as superoxide dismutase

\footnotetext{
${ }^{1}$ Sardar Patel University, N.V. Patel College of Pure and Applied Sciences, V.V. Nagar, 388120 Gujarat, India.

"Corresponding author (yachanajha@gmail.com).

${ }^{2}$ Sardar Patel University, BRD School of Biosciences, PO box 39, V.V. Nagar, 388120 Gujarat, India.

Received: 16 January 2013.

Accepted: 1 June 2013.

doi:10.4067/S0718-58392013000300002
}

(SOD), peroxidase (POX), and catalase (CAT), and nonenzymatic antioxidants such as ascorbate, glutathione, and $\alpha$-tocopherol (Del Rio et al., 2003). Salt-stressed plants accumulate various molecules found in organic matter such as proline, glucose, and glycine betaine as in quaternary compounds in the cytosol for osmoregulation to occur and thereby protecting macromolecules and enzyme activity. However, levels of such molecules are frequently used as indicators of oxidative stress in plants (Mittler, 2002). Induction of antioxidant enzymes by PGPR strain increases the tolerance of lettuce grown under severe salt stress, could serve as a useful tool to alleviate salt stress in salt-sensitive plants (Kohler et al., 2009). There have been a number of reports in the last decade on the beneficial effects of microorganisms such as Pseudomonas, Bacillus, Pantoea, Burkholderia, Rhizobium, which help to enhance crop tolerance to drought, salinity, heat stress, and chilling injury under controlled conditions in sunflower, maize, wheat, chickpea, groundnut, spices, and grapes (Arshad et al., 2008). Increasing salinity decreases plant growth, mineral uptake, and directly affects plant growth. This study was carried out to investigate the effects of isolated plant growth-promoting rhizobacteria (PGPR) on growth parameters, mineral concentration, as well as antioxidant level in paddy leaves under different soil saline conditions.

\section{MATERIALS AND METHODS}

\section{Salt stress condition}

Isolation, identification, and inoculation with PGPR in paddy plants were in accordance with our previously 
published method (Jha et al., 2011). Soil samples were collected from wet rice (Oryza sativa L.) fields that had the following physiochemical properties: $\mathrm{pH}, 7.79$; electrical conductivity, $1063 \mu \mathrm{S} \mathrm{cm}{ }^{-1}$; CEC, $3 \mathrm{cmol}$; organic $\mathrm{C}$, $5500 \mathrm{mg} \mathrm{kg}^{-1}$; available $\mathrm{N}, 200 \mathrm{mg} \mathrm{dm}^{-2}$; available Ca, $12.1 \mathrm{cmol}$; available P 205, $9.5 \mathrm{mg} \mathrm{dm}^{-2}$; available $\mathrm{K} 20$, $265 \mathrm{mg} \mathrm{kg}^{-1}$; Fe, $3.1 \mathrm{mg} \mathrm{kg}^{-1}$; Zn, $285 \mathrm{mg} \mathrm{kg}{ }^{-1}$; Mn, 3.7 $\mathrm{mg} \mathrm{kg}^{-1}$; and $\mathrm{Cu}, 2.2 \mathrm{mg} \mathrm{kg}^{-1}$. Five different salinity levels were maintained by adding $\mathrm{NaCl}$ solution $(0.5,1.0,1.5$, 2.0 , and $2.5 \mathrm{~g} \mathrm{NaCl} \mathrm{kg}^{-1}$ soil) to the pots. To avoid osmotic shock, the $\mathrm{NaCl}$ concentration was gradually increased for four consecutive days until the desired concentration was attained. A plastic bag was kept under each pot to collect excess water due to drainage. This water was reintroduced to the respective pot. All seedlings were grown for $4 \mathrm{wk}$ without any fertilizer treatment. The experiment was conducted in a greenhouse at 20 to $25{ }^{\circ} \mathrm{C}$ with a relative humidity of 70 to $80 \%$.

\section{Effect of PGPR on growth parameters under saline conditions}

Observations of physical parameters, that is, germination percentage, survival, plant height, and dry weight were recorded for three replicates from each treatment $45 \mathrm{~d}$ after sowing. Dry weight (DW) was determined by drying leaves and roots at $70{ }^{\circ} \mathrm{C}$ for $48 \mathrm{~h}$ and then weighing them.

\section{Effect of PGPR on foliar inorganic ion concentrations}

Paddy plant tissues were ground before chemical analysis. Foliar P contents were determined by colorimetry after digestion in nitric-perchloric acid (5:3) for $6 \mathrm{~h}$. Plant $\mathrm{K}$, $\mathrm{Na}$, and $\mathrm{Ca}$ were estimated by taking $1 \mathrm{~g}$ of plant material digested in tri-acid mixture, that is, sulfuric acid $\left(\mathrm{H}_{2} \mathrm{SO}_{4}\right)$, nitric acid $\left(\mathrm{HNO}_{3}\right)$, and perchloric acid $\left(\mathrm{HClO}_{4}\right)$ in a 9:3:1 ratio. The digested material was filtered and its aliquots were analyzed with specific filter in digital flame photometry. The $\mathrm{N}$ concentration was determined by colorimetry after Kjeldahl digestion.

\section{Enzyme extractions and assays}

Leaves ( $2 \mathrm{~g}$ ) were homogenized with a mortar and pestle in $4 \mathrm{~mL}$ of ice-cold $50 \mathrm{mM}$ Tris-acetate buffer with $\mathrm{pH}$ 6.0 containing $0.1 \mathrm{mM}$ ethylenediaminetetraacetic acid (EDTA), $5 \mathrm{mM}$ cysteine, $2 \%(\mathrm{w} / \mathrm{v})$ polyvinylpyrrolidone (PVP), $0.1 \mathrm{mM}$ phenylmethylsulfonyl fluoride (PMSF), and $0.2 \%(\mathrm{v} / \mathrm{v})$ Triton $\mathrm{X} 100$. The homogenate was centrifuged at $12000 \mathrm{~g}$ for $20 \mathrm{~min}$ and the supernatant was filtered through a Sephadex G-25 column with the same equilibration buffer used for homogenization. The column elution was used as an enzyme source to determine enzyme activity. All operations were performed at $4{ }^{\circ} \mathrm{C}$. Protein concentration was determined by taking OD at $595 \mathrm{~nm}$ with bovine serum albumin as a standard.

\section{Estimation of superoxide dismutase (SOD) activity}

Superoxide dismutase (SOD) activity was estimated spectrophotometrically as the inhibition of NBT photochemical reduction at $560 \mathrm{~nm}$. A reaction mixture (3 $\mathrm{mL}$ ) contained $33 \mathrm{mM}$ NBT, $10 \mathrm{mM}$ L-methionine, 0.66 $\mathrm{mM}$ EDTA, $\mathrm{Na}_{2}$, and $0.0033 \mathrm{mM}$ riboflavin in $0.05 \mathrm{M} \mathrm{Na}-$ phosphate buffer ( $\mathrm{pH} 7.8$ ), and $0.1 \mathrm{~mL}$ enzyme from the plant source. One unit of SOD is defined as the amount of enzyme that inhibits $50 \%$ NBT photo-reduction. Reactions were carried out at $25^{\circ} \mathrm{C}$ under light intensity at approximately $300 \mu \mathrm{mol} \mathrm{m}^{-2} \mathrm{~s}^{-1}$ for $10 \mathrm{~min}$. Details of the original method modifications are detailed in Costa et al. (2010). All tests were carried out in triplicate.

\section{Estimation of catalase (CAT) activity}

Catalase activity (CAT) was assayed by measuring the initial rate of $\mathrm{H}_{2} \mathrm{O}_{2}$ disappearance (Ramalingam and In-Jung, 2013). The reaction mixture consisted of $3 \%$ (v/v) $\mathrm{H}_{2} \mathrm{O}_{2}$ and $0.1 \mathrm{mM}$ EDTA in $0.05 \mathrm{M} \mathrm{Na}$-phosphate buffer ( $\mathrm{pH} 7$ ) and $0.1 \mathrm{~mL}$ enzyme from the plant source. The decrease in $\mathrm{H}_{2} \mathrm{O}_{2}$ was followed by the decline in optical density at $240 \mathrm{~nm}$; activity was calculated as the consumption of $\mu \mathrm{mol} \mathrm{H}_{2} \mathrm{O}_{2} \mathrm{~min}^{-1}$. All tests were carried out in triplicate.

\section{Estimation of peroxidase (POX) activity}

A leaf sample was homogenized in $1 \mathrm{~mL}$ of $0.1 \mathrm{M}$ phosphate buffer with $\mathrm{pH} 7.0$ at $4{ }^{\circ} \mathrm{C}$. The homogenate was centrifuged at $12000 \mathrm{~g}$ at $4{ }^{\circ} \mathrm{C}$ for $15 \mathrm{~min}$ and the supernatant used as the enzyme source. Peroxidase activity (POX) was determined as oxidation of $0.1 \mathrm{mM}$ ferulic acid with $1 \mathrm{mM} \mathrm{H}_{2} \mathrm{O}_{2}$ and $3.6 \mu \mathrm{g}$ of sample protein in $50 \mathrm{mM} \mathrm{K}$-phosphate buffer with $\mathrm{pH} 6.0$ at $30{ }^{\circ} \mathrm{C}$ (Hadži-Tašković Šukalović et al., 2005).

\section{Random Amplified Polymorphic DNA (RAPD) analysis of ' $G J-17$ '}

Random Amplified Polymorphic DNA (RAPD) analysis of 'GJ-17' was performed with known saltsensitive ('GAUR-100') and salt-resistant ('Dandhi') paddy varieties. The total genomic DNA of the three varieties was isolated. The isolated DNA was qualified and quantified by agarose gel electrophoresis and UV spectrophotometric methods. The RAPD profiles were generated with four decameric primers $(\mathrm{AH} 2, \mathrm{AH} 3, \mathrm{AH} 4$, and AH5) from MWG Bangalore, India. The reaction mixture contained $2 \mu \mathrm{L}$ primer $(0.3 \mu \mathrm{M}), 1$ unit Taq DNA polymerase, $0.5 \mu \mathrm{L} \mathrm{MgCl}_{2}, 2 \mu \mathrm{L} 4 \mathrm{dNTPs}, 5 \mu \mathrm{L} 10 \mathrm{X}$ assay buffer, $2 \mu \mathrm{L}$ DNA sample (100 ng), and adjusted to a final volume of $25 \mu \mathrm{L}$ with nuclease free water.

The RAPD-PCR reaction was performed in an Eppendorff thermocycler. The standard conditions for 35 cycles were initial denaturation temperature at $95^{\circ} \mathrm{C}$ for 1 min, denaturation temperature at $95^{\circ} \mathrm{C}$ for $30 \mathrm{~s}$, annealing temperature at $36^{\circ} \mathrm{C}$ for $1 \mathrm{~min}$, extension temperature at $72{ }^{\circ} \mathrm{C}$ for $1 \mathrm{~min}$, and the final extension at $72{ }^{\circ} \mathrm{C}$ for $5 \mathrm{~min}$. Amplified products were analyzed in $2 \%$ agarose gel. 


\section{RESULTS}

\section{Effect of PGPR on plant growth}

The effect of PGPR B. pumilus and P. pseudoalcaligenes were studied on physiological responses of paddy plants exposed to different levels of soil salinity by inoculating them either alone or combined. Germination, survival, plant height, and dry weight were significantly increased by the PGPR treatments under both non-saline and saline conditions (Table 1). At non-saline and $0.5 \%$ saline conditions, plants inoculated with PGPR showed increases in germination percentage ( $7 \%$ to $16 \%$ ), survival percentage (6\% to $8 \%$ ), dry weight (20\% to $27 \%$ ), and plant height (26\% to $31 \%$ ) as compared to non-inoculated control plants. At $1 \%$ salinity, plants inoculated with the mixture of PGPR showed marginal decreases in germination $(2.5 \%)$, survival $(9 \%)$, and plant height $(6 \%)$, while dry weight showed a marginal increase (1.2\%). Effectiveness of PGPR in overcoming the harmful effects of salinity was drastically decreased when salinity was more than $1 \%$.

\section{Effect of PGPR on foliar mineral concentrations}

The concentration of major mineral nutrients in rice leaves under soil saline conditions showed a significant variation in the PGPR treatment. Salinity significantly increased foliar $\mathrm{P}, \mathrm{Na}$, and $\mathrm{Ca}$ concentrations and decreased $\mathrm{N}$ and $\mathrm{K}$ concentrations in paddy plants (Table 2). The $\mathrm{N}$ concentration was higher in plants inoculated with both PGPRs under saline conditions. A gradual $\mathrm{N}$ concentration increase of $6 \%$ to $26 \%$ was recorded under non-saline conditions and this increase was observed up to $1 \%$ salinity; however, it decreased at higher salinity in inoculated plants. Plants inoculated with PGPR showed a $2.2 \%$ reduction in foliar $\mathrm{Na}$ concentration under nonsaline conditions and up to $73 \%$ under salinity conditions, while $\mathrm{P}$ concentration was $16 \%$ higher under non-saline conditions and $9.5 \%$ under soil saline conditions. At a moderate salinity level, foliar $\mathrm{N}$ and $\mathrm{P}$ concentrations showed an opposite trend, that is, plants inoculated with PGPR showed the highest P concentration and the lowest $\mathrm{N}$ concentration. Plants inoculated with both PGPRs showed a $21 \%$ higher $\mathrm{K}$ concentration under non-saline conditions and the highest concentration $(31 \%)$ of foliar $\mathrm{K}$ at the $0.5 \%$ salinity level. The K:Na ratio is always higher in plants inoculated with both PGPRs under nonsaline conditions as well as at different salinity levels. The concentration of $\mathrm{Ca}$ also gradually increased in plants inoculated with both PGPRs up to $0.5 \%$ salinity, but it decreased under higher salinity levels.

\section{Changes in enzymatic activity}

Catalase activity. Catalase activity decreased in plants inoculated with PGPR in the non-saline conditions and in non-inoculated plants under saline conditions. The highest CAT activity was observed in plants inoculated with both PGPRs grown with $2.5 \% \mathrm{NaCl}$. There was a 4 to $36 \%$ increased CAT activity in plants inoculated with PGPR in saline conditions (Figure 1).

Table 1. Effect of PGPRs on percentage germination, percentage survival, dry weight, and plant height under saline conditions in paddy 'GJ-17' at five different salinity levels $(n=5)$.

\begin{tabular}{|c|c|c|c|c|c|}
\hline $\begin{array}{l}\text { Salinity of } \\
\text { irrigation water }\end{array}$ & Treatment & Ger & jival & Dry weight & Plant height \\
\hline & & $\longrightarrow$ & - & g plant $^{-1}$ & $\mathrm{~cm}$ \\
\hline \multirow[t]{4}{*}{$0.0 \% \mathrm{NaCl}$ Control } & No inoculation & $71.1 \mathrm{~d}$ & $85.7 \mathrm{~d}$ & $2.43 \mathrm{~d}$ & $62.1 \mathrm{~d}$ \\
\hline & Inoculation with Bacillus pumilus & $75.4 \mathrm{bc}$ & $89.1 \mathrm{bc}$ & $2.68 \mathrm{c}$ & $69.3 \mathrm{c}$ \\
\hline & Inoculation with Pseudomonas pseudoalcaligenes & $76.8 \mathrm{~b}$ & $91.3 b$ & $2.87 \mathrm{ab}$ & $74.2 \mathrm{ab}$ \\
\hline & Inoculation with $B$. pumilus $+P$. pseudoalcaligenes & $82.2 \mathrm{a}$ & $93.2 \mathrm{a}$ & $2.93 \mathrm{a}$ & $78.4 \mathrm{a}$ \\
\hline \multirow[t]{4}{*}{$0.5 \% \mathrm{NaCl}$} & No inoculation & $68.1 d$ & $81.1 \mathrm{~d}$ & $2.03 \mathrm{~d}$ & $54.2 \mathrm{~cd}$ \\
\hline & Inoculation with $B$.pumilus & $70.2 \mathrm{bc}$ & $83.3 \mathrm{bc}$ & $2.23 \mathrm{c}$ & $61.4 \mathrm{c}$ \\
\hline & Inoculation with P.pseudoalcaligenes & 71.1ab & $84.7 b$ & $2.41 b$ & $68.5 b$ \\
\hline & Inoculation with $B$. pumilus $+P$. pseudoalcaligenes & $73.4 \mathrm{a}$ & $86.2 \mathrm{a}$ & $2.58 \mathrm{a}$ & $71.2 \mathrm{a}$ \\
\hline \multirow[t]{4}{*}{$1.0 \% \mathrm{NaCl}$} & No inoculation & $62.3 \mathrm{~cd}$ & $72.1 \mathrm{~d}$ & $1.98 \mathrm{~d}$ & $42.3 \mathrm{~d}$ \\
\hline & Inoculation with B.pumilus & $64.1 \mathrm{c}$ & $74.3 \mathrm{c}$ & $2.21 \mathrm{c}$ & $48.4 \mathrm{c}$ \\
\hline & Inoculation with $P$.pseudoalcaligenes & $66.1 b$ & $76.1 \mathrm{~b}$ & $2.34 \mathrm{~b}$ & $55.2 \mathrm{~b}$ \\
\hline & Inoculation with $B$. pumilus $+P$. pseudoalcaligenes & $69.2 \mathrm{a}$ & $78.4 \mathrm{a}$ & $2.46 \mathrm{a}$ & $58.6 \mathrm{a}$ \\
\hline \multirow[t]{4}{*}{$1.5 \% \mathrm{NaCl}$} & No inoculation & $55.2 \mathrm{~d}$ & $63.2 \mathrm{~d}$ & $1.73 d$ & $34.1 \mathrm{~d}$ \\
\hline & Inoculation with $B$.pumilus & $57.1 \mathrm{bc}$ & $64.1 \mathrm{bc}$ & $1.86 \mathrm{bc}$ & $37.5 \mathrm{bc}$ \\
\hline & Inoculation with P.pseudoalcaligenes & $58.3 b$ & $65.7 \mathrm{~b}$ & $1.98 \mathrm{~b}$ & $43.7 \mathrm{~b}$ \\
\hline & Inoculation with $B$. pumilus $+P \cdot$ pseudoalcaligenes & $61.2 \mathrm{a}$ & $67.4 \mathrm{a}$ & $2.12 \mathrm{a}$ & 47.1a \\
\hline \multirow[t]{4}{*}{$2.0 \% \mathrm{NaCl}$} & No inoculation & $32.4 \mathrm{~cd}$ & $42.5 \mathrm{~cd}$ & $1.52 \mathrm{~d}$ & $28.6 \mathrm{~d}$ \\
\hline & Inoculation with $B$.pumilus & $33.5 \mathrm{c}$ & $43.1 \mathrm{bc}$ & $1.74 \mathrm{c}$ & $31.4 \mathrm{c}$ \\
\hline & Inoculation with $P$.pseudoalcaligenes & $35.1 \mathrm{~b}$ & $43.9 \mathrm{ab}$ & $1.86 \mathrm{~b}$ & $37.2 \mathrm{ab}$ \\
\hline & Inoculation with $B \cdot$ pumilus $+P$.pseudoalcaligenes & $37.8 \mathrm{a}$ & $44.6 \mathrm{a}$ & $1.92 \mathrm{a}$ & $41.3 \mathrm{a}$ \\
\hline \multirow[t]{4}{*}{$2.5 \% \mathrm{NaCl}$} & No inoculation & $22.3 \mathrm{~d}$ & $32.2 \mathrm{~cd}$ & $1.21 \mathrm{~d}$ & $21.7 \mathrm{~d}$ \\
\hline & Inoculation with $B$. pumilus & $24.1 \mathrm{bc}$ & $32.6 \mathrm{bc}$ & $1.42 \mathrm{bc}$ & $26.3 \mathrm{c}$ \\
\hline & Inoculation with P.pseudoalcaligenes & $25.7 \mathrm{~b}$ & $33.1 \mathrm{ab}$ & $1.56 \mathrm{~b}$ & $32.4 \mathrm{~b}$ \\
\hline & Inoculation with $B$. pumilus $+P$. pseudoalcaligenes & $27.2 \mathrm{a}$ & $33.8 \mathrm{a}$ & $1.75 \mathrm{a}$ & $37.1 \mathrm{a}$ \\
\hline
\end{tabular}

For each parameter, values in columns followed by the same letter are not significantly different $(\mathrm{P} \leq 0.05)$. 
Table 2. Effect of PGPRs on mineral concentration under saline conditions in paddy 'GJ-17' at five different salinity levels ( $\mathrm{n}=5$ ).

\begin{tabular}{|c|c|c|c|c|c|c|c|}
\hline Salinity & Treatment & $\mathrm{N}$ & $\mathrm{P}$ & $\mathrm{K}$ & $\mathrm{Na}$ & $\mathrm{Ca}$ & $\mathrm{K}: \mathrm{Na}$ Ratio \\
\hline & & & & $\mathrm{mg} \mathrm{kg}^{-1}$ & & & \\
\hline \multirow[t]{4}{*}{$0.0 \% \mathrm{NaCl}$} & No inoculation & $19.1 \mathrm{~d}$ & $1885.1 d$ & $58710 \mathrm{~d}$ & $720.2 \mathrm{a}$ & $12674 \mathrm{ab}$ & 81.5 \\
\hline & Inoculation with Bacillus pumilus & $20.4 \mathrm{c}$ & $1939.1 \mathrm{bc}$ & $60131 \mathrm{c}$ & $714.3 \mathrm{ab}$ & $10541 \mathrm{~cd}$ & 84.2 \\
\hline & Inoculation with Pseudomonas pseudoalcaligenes & $23.8 \mathrm{ab}$ & $2091.3 b$ & $64223 b$ & $704.7 \mathrm{c}$ & $11787 \mathrm{c}$ & 91.2 \\
\hline & Inoculation with B.pumilus $+P$. pseudoalcaligenes & $24.2 \mathrm{a}$ & $2193.2 \mathrm{a}$ & $71142 \mathrm{a}$ & $691.3 \mathrm{~cd}$ & $13263 a$ & 102.9 \\
\hline \multirow[t]{4}{*}{$0.5 \% \mathrm{NaCl}$} & No inoculation & $22.4 \mathrm{~cd}$ & $1725.1 \mathrm{~d}$ & $54123 d$ & $787.1 \mathrm{a}$ & $15745 \mathrm{a}$ & 68.7 \\
\hline & Inoculation with $B$.pumilus & 23.1c & $1824.2 \mathrm{bc}$ & $61341 \mathrm{c}$ & $763.4 \mathrm{~b}$ & $12762 \mathrm{~cd}$ & 80.3 \\
\hline & Inoculation with P.pseudoalcaligenes & $26.3 b$ & $1891.8 b$ & $68250 \mathrm{~b}$ & $734.1 \mathrm{c}$ & $13771 b c$ & 92.9 \\
\hline & Inoculation with B.pumilus $+P$. pseudoalcaligenes & $27.3 \mathrm{a}$ & $1974.3 \mathrm{a}$ & $71322 \mathrm{a}$ & $724.6 \mathrm{~cd}$ & $14793 \mathrm{ab}$ & 98.5 \\
\hline \multirow[t]{4}{*}{$1.0 \% \mathrm{NaCl}$} & No inoculation & $23.1 \mathrm{~cd}$ & $1524.3 \mathrm{~cd}$ & $45132 d$ & $816.5 \mathrm{a}$ & $16591 \mathrm{a}$ & 55.3 \\
\hline & Inoculation with $B$.pumilus & $24.3 \mathrm{c}$ & $1625.2 \mathrm{c}$ & $47242 b c$ & $776.7 \mathrm{~b}$ & $12762 \mathrm{~cd}$ & 60.8 \\
\hline & Inoculation with P.pseudoalcaligenes & $27.2 \mathrm{~b}$ & $1745.2 \mathrm{~b}$ & $48121 \mathrm{ab}$ & $766.8 \mathrm{bc}$ & $13621 b c$ & 62.8 \\
\hline & Inoculation with B.pumilus $+P$. pseudoalcaligenes & $29.4 \mathrm{a}$ & $1862.1 \mathrm{a}$ & $49650 \mathrm{a}$ & $736.9 \mathrm{~d}$ & $14641 b$ & 67.4 \\
\hline \multirow[t]{4}{*}{$1.5 \% \mathrm{NaCl}$} & No inoculation & $18.3 \mathrm{~cd}$ & $2212.4 d$ & $39415 d$ & $864.3 \mathrm{a}$ & $17381 \mathrm{a}$ & 45.6 \\
\hline & Inoculation with $B$. pumilus & $19.5 \mathrm{c}$ & $2365.1 b c$ & $41153 b c$ & $764.5 b$ & $13394 \mathrm{~cd}$ & 53.8 \\
\hline & Inoculation with P.pseudoalcaligenes & $22.3 \mathrm{ab}$ & $2413.1 b$ & $43972 b$ & $724.6 \mathrm{c}$ & $14407 \mathrm{c}$ & 60.7 \\
\hline & Inoculation with B.pumilus $+P$. pseudoalcaligenes & $23.2 \mathrm{a}$ & $2546.3 \mathrm{a}$ & $44716 \mathrm{a}$ & $704.9 \mathrm{~cd}$ & $15236 b$ & 63.5 \\
\hline \multirow[t]{4}{*}{$2.0 \% \mathrm{NaCl}$} & No inoculation & $14.4 d$ & $2314.2 \mathrm{~cd}$ & $35162 d$ & $913.1 \mathrm{a}$ & $18310 \mathrm{a}$ & 38.5 \\
\hline & Inoculation with $B$.pumilus & $15.3 \mathrm{c}$ & $2415.2 \mathrm{c}$ & $36343 b c$ & $723.2 b$ & $13324 d$ & 50.2 \\
\hline & Inoculation with P.pseudoalcaligenes & $17.1 \mathrm{ab}$ & 2536.ab & $37320 \mathrm{ab}$ & $713.3 \mathrm{bc}$ & $15336 \mathrm{bc}$ & 52.3 \\
\hline & Inoculation with B.pumilus $+P$. pseudoalcaligenes & $17.9 \mathrm{a}$ & $2658.4 \mathrm{a}$ & 38835 & $695.5 d$ & $16834 b$ & 55.8 \\
\hline \multirow[t]{4}{*}{$2.5 \% \mathrm{NaCl}$} & No inoculation & $10.2 \mathrm{~cd}$ & 2458.1cd & $32174 d$ & 972.1a & 19221a & 33.1 \\
\hline & Inoculation with B.pumilus & $11.3 \mathrm{c}$ & $2547.4 \mathrm{bc}$ & $33232 \mathrm{c}$ & $682.2 b$ & $14728 d$ & 48.7 \\
\hline & Inoculation with P.pseudoalcaligenes & $13.6 \mathrm{~b}$ & 2638.1ab & $34241 \mathrm{ab}$ & $632.3 \mathrm{c}$ & $16234 \mathrm{bc}$ & 54.1 \\
\hline & Inoculation with B.pumilus $+P$. pseudoalcaligenes & $14.5 \mathrm{a}$ & $2698.7 \mathrm{a}$ & $35716 \mathrm{a}$ & $562.4 \mathrm{~d}$ & $17245 b$ & 63.5 \\
\hline
\end{tabular}

For each parameter, values in columns followed by the same letter are not significantly different $(\mathrm{P} \leq 0.05)$.

Superoxide dismutase (SOD) activity. The pattern of SOD activity was similar to that of the catalase enzyme. Salinity gradually and significantly increased in SOD activity in plants inoculated with PGPR. However, inoculation with PGPR resulted in decreased SOD activity under non-saline conditions. Unlike catalase enzyme activity, the highest increase in SOD activity at each $\mathrm{NaCl}$ concentration was observed in plants inoculated with PGPR. Plants inoculated with PGPR showed increased SOD activity that ranged from $7 \%$ to $69 \%$ in plants inoculated with PGPR at different salinity levels as compared to plants under non-saline conditions (Figure 2).

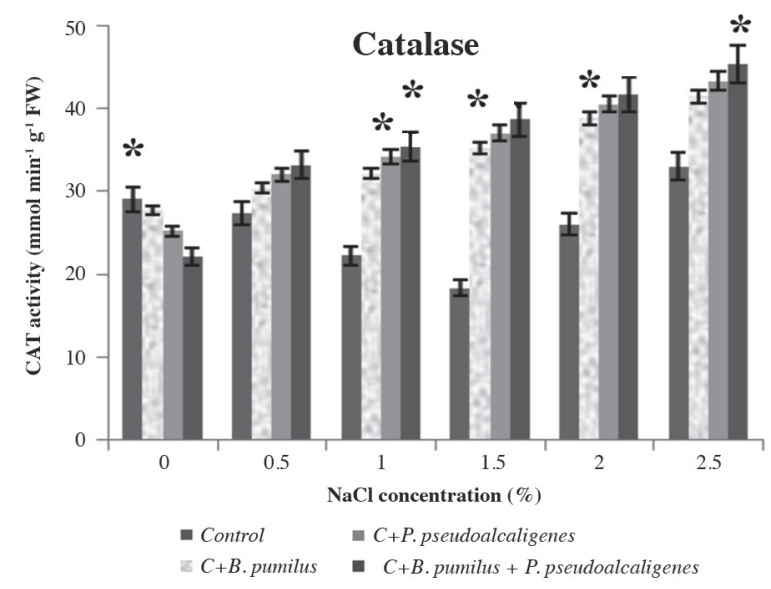

Figure 1. Effect of Bacillus pumilus and Pseudomonas pseudoalcaligenes on catalase (CAT) activity in paddy 'GJ-17' at five different salinity levels $(n=5)$.
Peroxidase (POX) activity. Peroxidase (POX) activity showed significant changes due to both salinity and PGPR inoculation. There was a direct correlation between salt concentration and POX activity. Peroxidase activity increased by $15 \%$ to $55 \%$ in plants inoculated with PGPR under non-saline conditions and $17 \%$ to $90 \%$ in noninoculated plants at different salinity levels as compared to pure control (non-inoculated plants under non-saline conditions) (Figure 3).

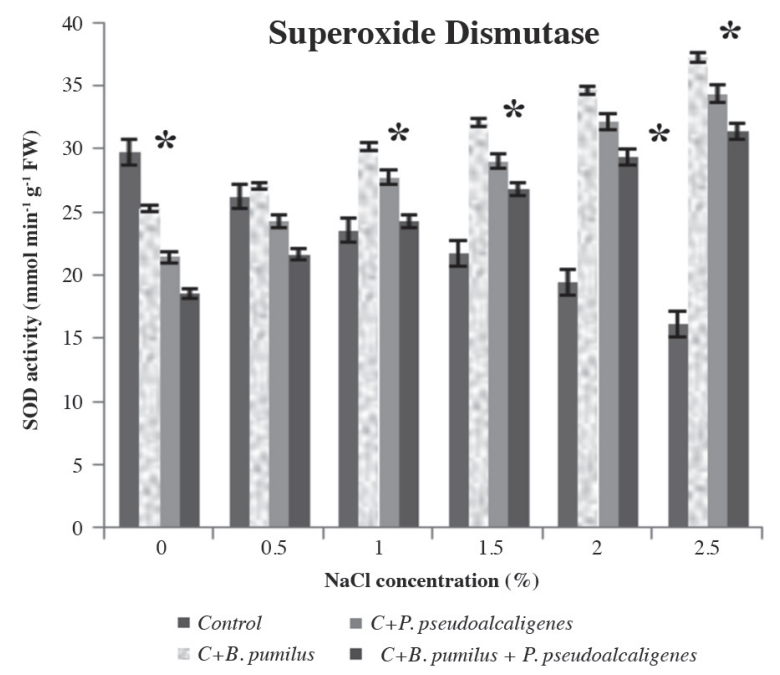

Figure 2. Effect of Bacillus pumilus and Pseudomonas pseudoalcaligenes on superoxide dismutase (SOD) activity in paddy 'GJ-17' at five different salinity levels $(\mathrm{n}=5)$. 


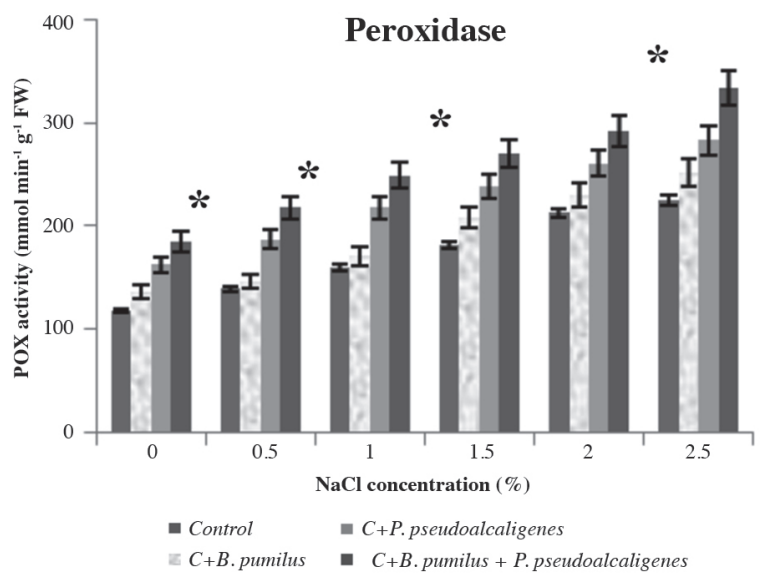

Figure 3. Effect of Bacillus pumilus and Pseudomonas pseudoalcaligenes on peroxidase (POX) activity in paddy 'GJ-17' at five different salinity levels $(n=5)$.

\section{Random Amplified Polymorphic DNA (RAPD) analysis}

Random Amplified Polymorphic DNA (RAPD) analysis of 'GJ-17' was done with the known salt-sensitive ('GAUR-100') and salt-resistant ('Dandhi') paddy varieties (Figure 4). A phylogenetic tree was constructed with Tree explorer 2.12, which clearly indicated that the paddy ' $\mathrm{GJ}-17$ ' is related to the salt-sensitive variety as shown in Figure 5.

\section{DISCUSSION}

Salinity adversely affects paddy growth regardless of the biological treatment and salt stress level. However, when plants were inoculated with PGPR in this study, the extent of growth suppression improved and the treated plants showed a greater growth response, which is supported by Han and Lee (2005a); improved dry weight as compared to non-inoculated control plants was also reported by Kohler et al. (2009). Results obtained from the present

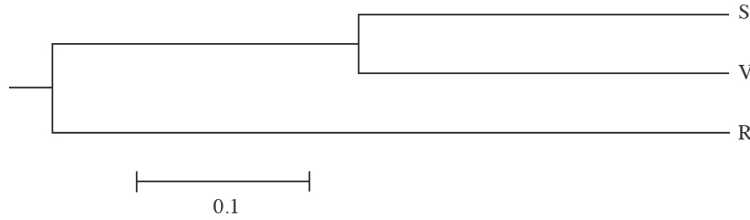

Figure 5. The phylogenetic tree constructed with Tree explorer 2.12 software indicated that paddy ' $G J-17$ ' $(\mathrm{V})$ is closely related to the sensitive 'GAUR-100' (S).

study indicate that seeds treated with P.pseudoalcaligenes and $B$. pumilus under saline conditions, as well as nonsaline conditions, showed higher germination and survival percentages as compared to non-treated seeds; similar findings were reported by Kumar et al. (2009). Plants inoculated at $1 \%$ salinity with the mixture of both PGPRs showed a marginal decrease in germination, survival, and plant height, while dry weight showed a marginal increase. At salinity higher than $1 \%$, the effectiveness of PGPR to overcome harmful effects of salinity was drastically decreased. The results of the present study also showed that such isolates help the plant to survive under adverse conditions.

The $\mathrm{N}$ concentration was higher in plants inoculated with both PGPRs under saline conditions. A gradual increase of $3 \%$ in $\mathrm{N}$ concentration was recorded at $1 \%$ salinity, which then decreased at higher salinity in inoculated plants. Foliar $\mathrm{Na}$ concentration was higher in the non-inoculated control plants, while $\mathrm{P}$ concentration was higher in plants inoculated with PGPR under soil saline conditions. Plants inoculated with PGPR alone and combined show higher foliar $\mathrm{K}$ levels. Potassium is an osmotically active solute that contributes to water absorption at the cell and whole plant level. It plays a key role in plant water stress tolerance and has been found to be the cationic solute responsible for stomatal movements in response to changes in bulk leaf water status (Caravaca et al., 2004). Giri et al. (2007) reported that an increase in $\mathrm{K}^{+}$concentration in plants under salt
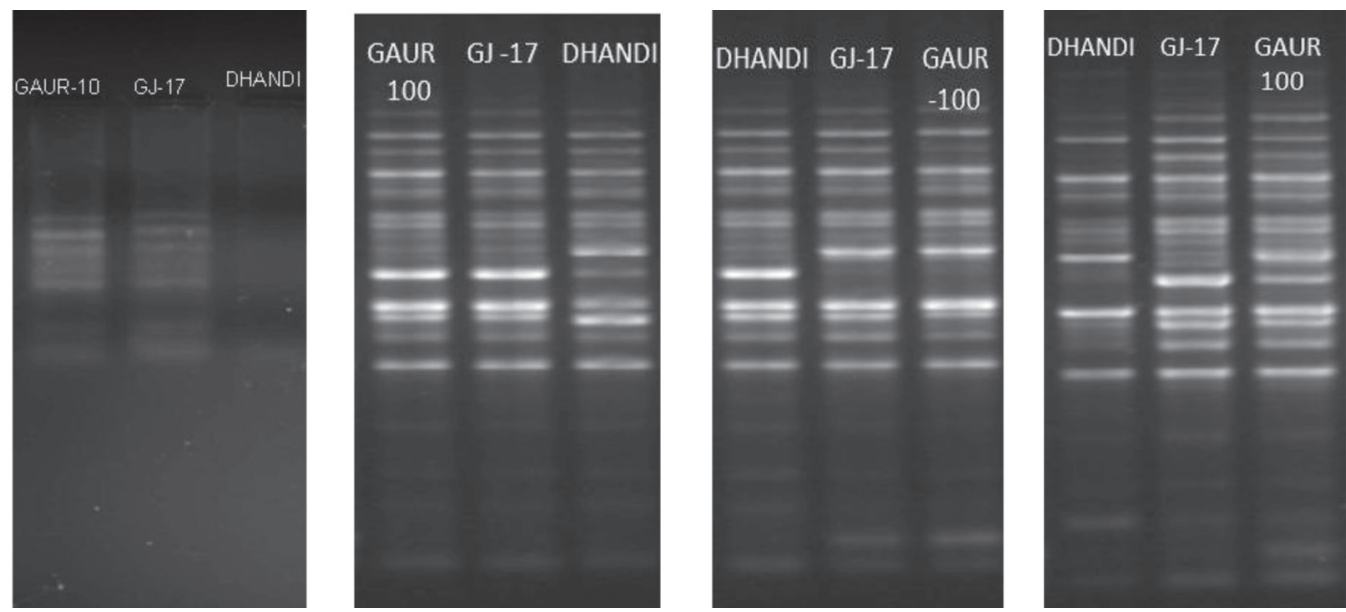

Figure 4. Agarose gels of RAPD analysis with AH2, AH3, AH4, and AH5 primers for 'GJ-17' with the known salt-sensitive ('GAUR-100') and salt-resistant ('Dandhi') paddy varieties. 
stress could heighten the harmful effects of salinity on growth and yield. Moreover, the present study showed that high $\mathrm{NaCl}$ concentrations increase the $\mathrm{Na}^{+}$and $\mathrm{Ca}^{2+}$ ratios in non-inoculated plants; these would then be more susceptible to osmotic and specific ion injury along with nutritional disorders that result in reduced yield and quality, which was also reported by Sivritepe et al. (2003). However, inoculation with PGPR reduced foliar $\mathrm{Na}^{+}$and $\mathrm{Ca}^{2+}$ concentrations in paddy plants (Table 2). The most important finding of this study was that cation uptake was reduced paddy plants inoculated with PGPR, which helps to alleviate salt stress in plants; this is in accordance with observations by Ashraf et al. (2004) There are several reports of lower $\mathrm{Na}^{+}$concentrations in plants inoculated with PGPR under saline conditions (Giri and Mukerji, 2004; Sharifi et al., 2007). Salttolerant monocotyledonous plants accumulate less $\mathrm{Na}$ in their leaves than salt-sensitive plants (El-Hendawy et al., 2005) and the $\mathrm{K}: \mathrm{Na}$ ratio has been considered as a tolerance index. The increased $\mathrm{K}: \mathrm{Na}$ ratio in the present study indicates the enhanced tolerance of paddy rice after PGPR inoculation. Colmer et al. (2005) reported that the $\mathrm{K}: \mathrm{Na}$ ratio is higher in tolerant rice and wheat genotypes. These observations clearly suggest that inoculation of $P$. pseudoalcaligenes and $B$. pumilus can improve the salttolerant ability of paddy plants to differentially reduce the harmful effects of salt stress.

The peroxidase (POX), catalase (CAT), and membrane stability index (MSI) are important common indices to evaluate the redox status of plants. The increased activities of antioxidant enzymes act as a damage control system and thus provide protection from oxidative stress, which otherwise could cause lipid peroxidation resulting in damage to the cell membrane and organelles, protein and DNA structure, inhibit photosynthesis, and other enzyme activities. Increasing salt stress significantly affects CAT, POX, and SOD activity in plants inoculated with PGPR and non-inoculated plants. Han and Lee (2005b) reported that under saline conditions, non-inoculated plants had an increased antioxidant activity as compared with plants inoculated with PGPR. The induction of antioxidant enzymes, such as catalase, peroxidase, and superoxide dismutase, can be considered as a salt-tolerant mechanism in paddy plants. These antioxidant enzymes are involved in eliminating $\mathrm{H}_{2} \mathrm{O}_{2}$ from salt-stressed plants. In the present study, reduction in CAT activity under salt stress conditions in the non-inoculated paddy plants, as well as in inoculated plants under non-saline conditions, can be due to the free radical scavengers, which could be attributed to decreased $\mathrm{H}_{2} \mathrm{O}_{2}$ levels that are not sufficient to activate the enzyme's antioxidant property. The highest CAT activity was observed in plants inoculated with both PGPRs grown with 2.5\% NaCl. Kumar et al. (2003) reported that salt stress inhibited CAT and POX activity, but activity of these enzymes was significantly higher in the presence of PGPR than in their absence. Peroxidase activity increased in plants inoculated with PGPR in nonsaline conditions and in non-inoculated plants at different salinity levels.

Increased CAT activity at high salinity levels and POX activity in plants inoculated with PGPR at different salinity levels point to a signaling role of $\mathrm{H}_{2} \mathrm{O}_{2}$ in the induction of $\mathrm{H}_{2} \mathrm{O}_{2}$ detoxifying enzymes in rice leaves, which was reported for other abiotic stresses by Sairam et al. (2005).

In the present study, SOD activity decreased under saline conditions in paddy plants inoculated with PGPR perhaps for its recovery of free radical scavengers due to the generation of oxidative stress by $\mathrm{H}_{2} \mathrm{O}_{2}$ and the possible inactivation of SOD as reported by Panda and Patra (2000). Plants inoculated with PGPR showed increased SOD activity at different salinity levels. In paddy plants inoculated with PGPR, decreased SOD activity was observed in this present study, which suggests a lower $\mathrm{O}_{2}^{-}$scavenging and dismutating capacity in this saltsensitive cultivar and signifies a possible involvement of this enzyme in salt tolerance in accordance with Dureja (2003).

The RAPD analysis of paddy 'GJ-17' showed more similarity with the known salt-sensitive 'GAUR-100', while inoculation with PGPR provides this paddy with the ability survive very well up to $1 \%$ salinity level.

Salt stress can induce a combination of negative effects on salt-sensitive paddy varieties including osmotic stress, ion toxicity, and oxidative stress. The present study indicates that the regulation of antioxidant enzymes is involved in the higher effectiveness of plants inoculated with PGPR with respect to increasing paddy 'GJ-17' tolerance to severe salt stress. The present study was also supported by our previous study on the accumulation of osmoprotectants in plants influenced by PGPR inoculation under salt stress conditions.

\section{CONCLUSIONS}

In conclusion, our report is significant to understand the induction of antioxidant enzymes in paddy plants under saline conditions. We postulate in our study that stressrelated antioxidant enzymes could be induced prior to biotic and abiotic stress, that is, only by PGPR inoculation. Our results conclude that inoculation of plant material with PGPR can protect paddy plants against salt stress. These effects correlate with an increase in plant growth parameters and the regulation of ion concentration and antioxidant enzymes.

\section{LITERATURE CITED}

Arshad, M., B. Shaharoona, and T. Mahmood. 2008. Inoculation with Pseudomonas spp. containing ACC-deaminase partially eliminates the effects of drought stress on growth, yield and 
ripening of pea (Pisum sativum L.) Pedosphere 18:611-620.

Ashraf, M., S.H. Berge, and O.T. Mahmood. 2004. Inoculating wheat seedlings with exopolysaccharide-producing bacteria restricts sodium uptake and stimulates plant growth under salt stress. Biology and Fertility of Soil 40:157-162.

Caravaca, F., D. Figueroa, J.M. Barea, C. Azcón-Aguilar, and A. Roldán. 2004. Effect of mycorrhizal inoculation on the nutrient content, gas exchange and nitrate reductase activity of Retama sphaerocarpa and Olea europaea subsp. sylvestris under drought stress. Journal of Plant Nutrients 27:57-74.

Colmer, T.D., R. Munns, and T.J. Flowers. 2005. Improving salt tolerance of wheat and barley: future prospects. Australian Journal of Experimental Agriculture 45:1425-1443.

Costa, M.A., H.A. Pinheiro, E.S.C. Shimizu, F.T. Fonseca, Santos, B.G. dos Santos Filho, et al. 2010. Lipid peroxidation, chloroplastic pigments and antioxidant strategies in Carapa guianensis (Aubl.) subjected to water-deficit and short-term rewetting. Tree 24:275-283.

De Pinto, M.C., V. Locato, and L. De Gara. 2012. Redox regulation in plant programmed cell death. Plant Cell and Environment 35:234-244.

Del Rio, L.A., F.J. Corpas, L.M. Sandalio, J.M. Palma, and J.B. Barroso. 2003. Plant peroxisomes, reactive oxygen metabolism and nitric oxide. IUBMB Life 55:71-81.

Dureja, V. 2003. Effect of salinity stress on antioxidant enzymes in salt-tolerant and salt-sensitive cultivar of rice (Oryza sativa L.) MSc Thesis. CCS Haryana Agricultural University, Hisar, India.

El-Hendawy, S.E., Y. Hu, and U. Schmidhalter. 2005. Growth, ion content, gas exchange, and water relations of wheat genotypes differing in salt tolerances. Australian Journal of Agricultural Research 56:123-134.

Foyer, C.H., and G. Noctor. 2005. Redox homeostasis and antioxidant signaling: a metabolic interface between stress perception and physiological responses. Plant and Cell 17:1866-1875.

Giri, B., R. Kapoor, and K.G. Mukerji. 2007. Improved tolerance of Acacia nilotica to salt stress by arbuscular mycorrhizal, Glomus fasciculatum may be partly related to elevated $\mathrm{K} / \mathrm{Na}$ ratios in root and shoot tissues. Microbial Ecology 54:753-760.

Giri, B., and K.G. Mukerji. 2004. Mycorrhizal inoculant alleviates salt stress in Sesbania aegyptiaca and Sesbania grandiflora under field conditions, evidence for reduced sodium and improved magnesium uptake. Mycorrhiza 14:307-312.

Hadži-Tašković Šukalović, V., M. Vuletić, and Z. Vučinić. 2005. The role of p-coumaric acid in oxidative and peroxidative cycle of the ionically bound peroxidase of the maize root cell wall. Plant Science 168:931-938.

Han, H.S., and K.D. Lee. 2005a. Plant growth promoting rhizobacteria. Effect on antioxidant status, photosynthesis, mineral uptake and growth of lettuce under soil salinity. Research Journal of Agriculture and Biological Sciences 1:210-215.

Han, H.S., and K.D. Lee. 2005b. Physiological responses of soybean. Inoculation of Bradyrhizobium japonicum with PGPR in saline soil conditions. Research Journal of Agriculture and Biological
Sciences 1:216-221.

Jha, Y., R.B. Subramanian, and S. Patel. 2011. Combination of endophytic and rhizospheric plant growth promoting rhizobacteria in Oryza sativa shows higher accumulation of osmoprotectant against saline stress. Acta Physiologiae Plantarum 33:797-802.

Kohler, J., F. Caravaca, M.M. Alguacil, and A. Roldán. 2009. Elevated $\mathrm{CO}_{2}$ increases the effect of an arbuscular mycorrhizal fungus and a plant-growth-promoting rhizobacterium on structural stability of a semiarid agricultural soil under drought conditions. Soil Biology and Biochemistry 41:1710-1716.

Kumar, S.G., A.M. Reddy, and C. Sudhakar. 2003. $\mathrm{NaCl}$ effects on proline metabolism in two high yielding genotypes of mulberry (Morus alba L.) with contrasting salt tolerance. Plant Science 165:1245-1251.

Kumar, A., S. Sharma, and S. Mishra. 2009. Effect of alkalinity on growth performance of Jatropha curcas inoculated with PGPR and AM fungi. Journal of Phytology 1:177-184.

Li, J.Y., A.L. Jiang, and W. Zhang. 2007. Salt stress-induced programmed cell death in rice root tip cells. Journal of Integrated Plant Biology 49:481-486.

Miller, G., N. Suzuki, N. Ciftci-Yilmazi, and R. Mittler. 2010. Reactive oxygen species homeostasis and signaling during drought and salinity stresses. Plant Cell and Environment 33:453467.

Mittler, R. 2002. Oxidative stress, antioxidants and stress tolerance. Trends in Plant Sciences 7:405-410.

Panda, S.K., and H.K. Patra. 2000. Does chromium(III) produce oxidative damage in excised wheat leaves? Journal of Plant Biology 27:105-110.

Ramalingam, R., and L. In-Jung. 2013. Ameliorative effects of spermine against osmotic stress through antioxidants and abscisic acid changes in soybean pods and seeds. Acta Physiologiae Plantarum 35:263-269.

Sairam, R.K., G.C. Srivastava, S. Agarwal, and R.C. Meena. 2005. Differences in antioxidant activity in response to salinity stress in tolerant and susceptible wheat genotypes. Biologia Plantarum 49:85-91.

Sharifi, M., M. Ghorbanli, and H. Ebrahimzadeh. 2007. Improved growth of salinity stressed soybean after inoculation with salt pretreated mycorrhizal fungi. Journal of Plant Physiology 164:11441151 .

Sivritepe, N., H.O. Sivritepe, and A. Eris. 2003. The effects of $\mathrm{NaCl}$ priming on salt tolerance in melon seedlings grown under saline conditions. Scientia Horticulturae 97:229-237.

Zhu, J., X. Fu, Y.D. Koo, and J.K. Zhu. 2007. An enhancer mutant of Arabidopsis salt overly sensitive 3 mediates both ion homeostasis and the oxidative stress response. Molecular and Cell Biology 27:5214-5224. 